\title{
Innovative model of business process reengineering at machine building enterprises
}

\author{
Roman Yu. Nekrasov ${ }^{1, *}$, Yulia A. Tempel ${ }^{1}$, Olga A. Tempel ${ }^{1}$, and Boris V. Barbyshev ${ }^{1}$ \\ ${ }^{1}$ Industrial University of Tyumen, 625000, Volodarskogo str., 38, Tyumen, Russian federation
}

\begin{abstract}
The paper provides consideration of business process reengineering viewed as a managerial innovation accepted by present day machine building enterprises, as well as ways to improve its procedure. A developed innovative model of reengineering measures is described and based on the process approach and other principles of company management.
\end{abstract}

\section{Introduction}

Machine building is one of the key industries in Russia. It is the branch which has provided approximately $15 \%$ GDP over the last four years. Machine building is also a resource base for scientific and technical progress. However, innovation activities at machine building enterprises are still at a quite low level. Only $8 \%$ of machine building products can be considered as conditionally innovative ones.

Therefore, upgrading the process base of the industry with up to date and prospective technologies, development of innovative products, improvement of machine building competitive ability on the whole, and conversion to the innovative model of economic development are of considerable importance in the scope of the programs aimed at modernization of Russian economy up to the year 2010.

Although production and process technologies have undergone significant transformations and IT technologies are used widely for managerial purposes, a lot of companies still rely on old and traditional principles of management as they usually did. As a consequence, innovative managerial decisions are to be introduced everywhere as innovations in management are far more inexpensive than those in technology. Furthermore, experts of the European Commission claimed that in the short run innovations in management would be of high importance for improvement of the competitive ability on the global market. The direct search for innovative products should be replaced by managerial innovations in these conditions; and that is a mainstream of strategic transformations in any company.

\section{Organization management}

The article presents the results of fundamental research on the role of administrative innovations in the field of machine-building production. In this study we were used to achieve a systemic approach that implements the review of the engineering enterprise as a complex hierarchical system, as well as the process approach to management. The dialectical method has allowed to carry out understanding of the specifics of modern organizations through innovative development and management.

The theoretical base of the research were scientific statements and conclusions set forth in the works of foreign scientists in the field of business process reengineering. Business process reengineering is one of innovative managerial technologies.

The work is becoming more urgent since nowadays the innovative development in the Russian industry faces some challenges, as stated before.

Moreover, reengineering, being one of the managerial innovations, is gaining in popularity because it alternates the way of business process implementation, making it more efficient, resulting, therefore, in a significant cut in expenditures, better manufacturing capability, improvement of quality, decrease in failures, losses or wastes, reduction of the employed staff (due to automation) and the increasing level of customer satisfaction.

At the same time its implementation is associated with diverse problems which might cause failures as demonstrated by the global experience and studies $[1,3$, 5].

Everything mentioned above was relevant for selecting the research domain - business process reengineering.

The study aims to support the methodology of reengineering viewed as an innovation in process and systematic approaches.

Revolutionary processes of efficiency and performance improvement, automation and management optimization are based on reengineering business processes which makes it possible to cut production costs, increase efficiency of the applied machinery and equipment, improve quality of products and decrease the quantity of output that does not meet particular

\footnotetext{
* Corresponding author: nekrasovri@tyuiu.ru
} 
requirements, advance customer satisfaction, and contribute to the competitive ability of the enterprise on the whole. Despite a number of advantages listed above the world practice demonstrates that this method involving a rigorous business rearrangement has some drawbacks as well.

Insufficient reengineering might be the reason for using inefficient methods in implementing algorithms of these measures. Although various models of reengineering implementation are available, a conclusion based on their analysis was made that they have a number of disadvantages, including the lack of the total control over each phase implementation, no interrelation between results of the first and final reengineering phases, the use of more general principles of this process, no concrete plan of works and appointment of employees responsible for their implementation, as well as no methods and possible means of reengineering on all its phases which would contribute to more efficient and resultant achievement of the specific goals and objectives. The shortcomings above can be eliminated fully or partially if reengineering is considered in terms of the process approach, i.e. implemented as a set of interdependent subprocesses (phases).

To reveal main trends, principles, methods and technologies of reengineering, and its implementation some algorithms were compared [1, 3, 4, 6], the conclusions below were made on the base of the obtained results.

If viewed as product life-cycle phases, a project of reengineering like any other project has its initial (preproject) phase, phase of development, implementation and completion. All the studied methodologies of reengineering are similar in this aspect $[1,3,4,6]$.

The majority of the analyzed algorithms comprise four basic phases: preparation, analysis of the current situation in the company, reengineering implementation, introduction of a new business model; all of them are called differently though the content is similar.

As for the shortcomings of the available algorithms, these include no control of business process reengineering implementation and no strategic planning, as well as efficiency and performance of the taken measures can't be estimated. Furthermore, the authors have not addressed to all phases interrelation; the scopes of reengineering subprocesses are also not determined. Some measures are only listed within each phase, and technologies of their fulfillment are provided without describing methods and means of attaining goals. Agents and project participants are assigned though their particular responsibilities within the project of reengineering are not given. There is no constant improvement of the business processes. Moreover, some algorithms are not systematized; all their phases are not exactly defined and measures are not logical. The principles are also not available which measures of business process reengineering should be relied on

Therefore, all the above drawbacks point to the fact that there is no proper algorithm available which can be used for the purpose of reengineering at any company; as a consequence it influences quality, efficiency and performance of business process reengineering, resulting sometimes in failures when implementing and significant financial and economic losses of the company.

The most of the present day companies are organized functionally, i.e. they have either a linear-functional or functional organization of management.

\section{Results and discussion}

The divisions in such organizations depend on their functions, but their relations with other divisions are not clear. The management considers subordination of subdivisions and the staff. This form of organizational structure fails to respond fast to strict requirements of the present day market.

First of all, it is caused by lacking relations between divisions of the company and its strategic goals, that is why, the form of company management in the scope of the process approach is regulated by the international standard ISO 9001. It makes urgent the use of process management and planning organizational transformations at the level of industrial complexes and corporations, implemented on the base of reengineering methods and principles. The organization here should be considered as an open system, as a complex of interrelated elements, such as personnel, structure, objectives and technologies which are oriented at fast responding to the challenges arising both in the company and out of it (external environment).

To sum up everything stated above it is necessary to systematize these measures, considering reengineering as a process which consists of several sub-processes (phases) aimed at reduction of possible failures when implementing.

To improve efficiency and performance of enterprises and corporations in various industries of Russian and global economy an algorithm of business process reengineering implementation is proposed which relies on theoretical fundamentals of business process reengineering and international standards ISO 9000.

The developed algorithm can be used in the following fields of economic activities: planning, development and testing of new products, purchases, logistics, marketing research, sales, management of relations with customers and suppliers, production processes etc.

The model of reengineering implementation is given in Figure 1.

This model comprises nine phases: preparation, development of the company model, selection and analysis of business processes, strategic planning, and the development of a new business (innovative idea), approval of the innovative idea, introduction of a new model, control, and continuous improvement. Moreover, this model takes consideration of conditions and principles of reengineering implementation, as well as the scheme of its phases with the definite action sequence. 


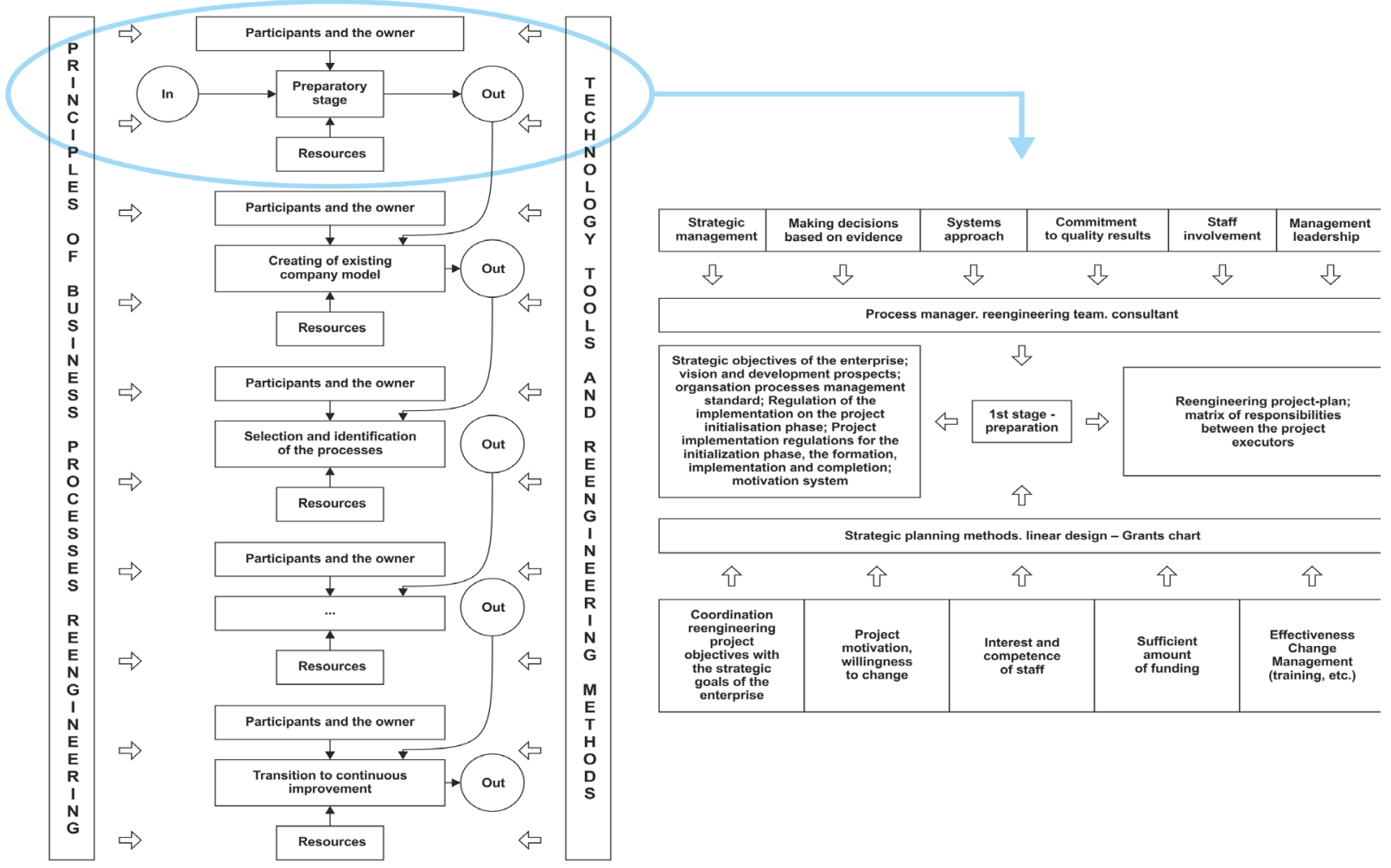

Fig. 1. The proposed innovative model of business project reengineering implementation

When developing the model under consideration a plan of works was framed for each phase as a Gantt chart. The schedule-plan can be specified and adjusted for different enterprises, depending on the type and kind of production, branch, economic activity and purposes of reengineering.

Furthermore, inputs and outputs were determined for each phase with respect to objectives and goals of the subprocess; that makes it possible to see the interdependence of the phases, since they are shown as sub-processes, where each subsequent output is an input for the other process (phase).

The initial input of reengineering implementation is a developed organization standard in the field of project management and regulations of project implementation in phases, it helps to determine the responsibilities of the project manager, heads of functional subdivisions, their rights and duties, this way a lot of conflicts might be avoided. Alongside with the standard in the field of project management a system of motivation is to be formed. The analysis of available motivation theories has revealed that Herzberg's two-factor motivation theory is the most efficient one, it allows encouraging of employees for actions in the scope of their professional activities by means of both motivating factors which are more important for their motivation and work conditions which hardly influence the satisfaction, but decline it if absent.

The developed model of business process reengineering also provides certain methods and means which further implementation of a particular phase; they include Gantt chart, SWOT-analysis and Porter's model to determine one's own competitive ability.
To implement each phase agents and participants are required: a leader - a top manager who approves the reengineering project and motivates; an organizational committee - a body consisting of managers who develop a general strategy of reengineering and monitor its implementation; a process manager - a person responsible for business processes and their reengineering; a team carrying out reengineering - a group of people who conduct diagnostics of the available process, its rearrangement and introduction of new rules; a consultant - a participant who is engaged in the development of reengineering methods and instruments.

Besides the above characteristics of the developed model the principles are of significant importance, which influence the key success factors of reengineering implementation. It is stated in international standards ISO 9000 that the principles of successful, efficient, and resultant reengineering comprise: strategic management; making fact-based decisions; process approach; systematic approach; orientation towards a consumer; personnel involvement, leadership of managers, and ambition for success.

\section{Conclusions}

The proposed model makes it possible to meet certain conditions of successful reengineering, such as coordination of project goals with the strategic purposes of the company, motivation of a new business model introduction, efficient and total control of changes, technological and methodical support, requirements of internal and external environment, sufficiency of provided resources for the project of business process 
reengineering, as well as determination of all phases and interdependence of their implementation.

Furthermore, the approach under consideration helps to allocate basic resources, methods and means which are necessary for implementation of a phase, its principles and technologies.

The proposed process-oriented model of reengineering algorithm is an idea of strategic innovative management of company development and comprises systematic and process approaches which form a new notion of company management in the long-run perspective. This approach makes it possible to improve the interaction of subdivisions, increase efficiency and performance of the introduced measures due to logical consequence of actions, strict recourse and responsibility division at each phase.

The work has a certain practical value, i.e. development of the business process reengineering model which helps to meet definite requirements of successful reengineering and improve interaction of the subdivisions. Furthermore, it increases efficiency and performance of the introduced measures due to logical sequence of actions and strict division of recourses and responsibilities at each phase.

\section{References}

1. D.Z. Liu, M. Liu, P.S. Zhong, Advances in Materials Manufacturing Science and Technology; Jinan; China; 18 September 2004, Volume 471-472, P. 770774 (2004)

2. A.A. Datsyk, S.I. Grudina, S.G. Avdonina, A.I. Podgornaya, Topical issues of influence of "contraction reengineering" on structure of business management: Academy of Strategic Management Journal Volume 15, Issue Special Issue 1, P. 67-82 (2016)

3. I. Verboncu, A.A. Fucec, A.I. Serban, M. Rusu, Association Conference - Innovation Management and Education Excellence Vision 2020: From Regional Development Sustainability to Global Economic Growth, IBIMA, P. 753-764 (2016)

4. H. A Lal Bhaskar, International Journal of Productivity and Quality Management, Volume 19, Issue 1, P. 98-115 (2016)

5. D.Grant, Business analysis techniques in business reengineering: Business Process Management Journal, Volume 22, Issue 1, P. 75-88. (2016) 